Gut, 1975, 16, 999-1005

\title{
Effect of secretin on release of heterogeneous forms of gastrin
}

\author{
EUGENE STRAUS, ADRIAN J. GREENSTEIN, AND ROSALYN S. YALOW1 \\ From the Solomon A. Berson Research Laboratory, Veterans Administration Hospital, Bronx, New \\ York, and Mount Sinai School of Medicine, CUNY, USA
}

SUMMARY The effect of an intravenous injection of secretin on plasma gastrin concentrations is shown to be dependent upon the relative concentrations of the major forms of immunoreactive gastrin present in the plasma at the time of injection. Secretin suppressed gastrin secretion in the fasting state in patients in whose plasma heptadecapeptide and big gastrins predominated and did not suppress when big big gastrin comprised more than $90 \%$ of plasma gastrin immunoreactivity. The post-secretin decrease in plasma gastrin was due entirely to the disappearance of the smaller, more rapidly degraded forms. Food-stimulated gastrin response was suppressed by secretin for the initial 40 minutes after a test meal but was greater than usual from 40 to 120 minutes.

The role of secretin in the regulation of gastrin secretion remains controversial. Some investigators (Hansky et al., 1971) have held that secretin suppresses gastrin release in the basal state, while others have observed that secretin suppressed food-stimulated gastrin release but had no effect on basal levels in normal subjects (Thompson et al., 1972). It has been demonstrated that plasma gastrin is heterogeneous, consisting of at least three different hormonal forms: heptadecapeptide gastrin (HG) originally isolated and purified by Gregory and Tracy (1964), big gastrin (BG), first demonstrated by fractionation of plasma and tissue immunoreactive gastrin (Yalow and Berson, 1970a; Berson and Yalow, 1971) and subsequently shown to be a 34 amino acid peptide (Gregory and Tracy, 1973), and 'big big' gastrin (BBG) which elutes in the void volume on Sephadex G-50 gel filtration (Yalow and $\mathrm{Wu}, 1973$ ) but which has not as yet been purified or chemically identified. Rehfeld et al. (1974) have observed two other relatively minor components of immunoreactive gastrin in the plasma of patients with Zollinger-Ellison syndrome and pernicious anaemia (PA): component $I$, intermediate in size between BG and BBG, and a component (IV) which is smaller than HG and presumed to be minigastrin. They have not investigated plasma

\footnotetext{
${ }^{1}$ Address for reprint requests: Veterans Adminsitration Hospital, 130 West Kingsbridge Road, Bronx, New York, 10468 U.S.A.

Received for publication 30 July 1975.
}

samples from normal subjects in the fasting state. The different hormonal forms have markedly different turnover rates (Straus and Yalow, 1974; Walsh et al., 1974). Thus the possibility is suggested that these discrepant results on suppression of gastrin release by secretin could be resolved by investigations which considered the hormonal forms of gastrin predominating in the plasma at the time the secretin was administered.

The present studies were designed to determine the effect of a bolus injection of secretin on basal and food-stimulated gastrin release, including consideration of the relative abundance of the various components of plasma gastrin.

\section{Methods}

After an overnight fast, basal gastrin levels and gastrin responses to intravenous injection of Boots secretin were studied in 22 control subjects-that is, those with neither history of acid peptic disease nor prior gastrointestinal surgery. Secretin testing was performed as part of a diagnostic work-up for each control subject. After the collection of basal plasma samples, a bilumened gastroduodenal tube was positioned fluoroscopically for collection of gastric and duodenal juices. After intravenous administration of 1 unit Boots secretin/ $\mathbf{k g}$ body weight, plasma samples were obtained at $5,10,15$, $20,30,40,60$, and 80 minutes. In each case the test was repeated with a dose of 4 units $/ \mathrm{kg}$ one hour 
after completion of the first test. Three patients with pernicious anaemia (PA) were also studied. One PA patient had only a 4 unit $/ \mathrm{kg}$ test.

The effect of secretin on food stimulated gastrin release was studied in seven subjects who ingested a standard test meal followed two hours later by a bolus injection of 4 units Boots secretin $/ \mathrm{kg}$ immediately preceding another test meal. The standard test meal was the one usually employed in this laboratory to study gastrin release (Walsh et al., 1971; Straus et al., 1974). It consisted of two hardboiled eggs, one slice of dry white toast, and $120 \mathrm{ml}$ of orange juice.

Plasma gastrin concentrations were measured by radioimmunoassay (RIA) techniques previously described (Yalow and Berson, 1970b). Fasting plasma specimens from 12 control subjects in whom fasting gastrin concentrations were $50 \mathrm{pg} / \mathrm{ml}$ or greater were fractionated by Sephadex G-50 gel chromatography. Specimens from the three PA patients were fractionated both on Sephadex gel chromatography and on starch gel electrophoresis. Plasma samples were fortified with marker molecules ( $\mathrm{Na}{ }^{131}$ I and 131I-human serum albumin) and were then fractionated by gel filtration on Sephadex G-50 fine columns $(1 \times 50 \mathrm{~cm})$ eluted with $0.02 \mathrm{M}$ barbital buffer fortified with $2.5 \mathrm{mg}$ salt-poor human serum albumin per $\mathrm{ml}$. Successive $1 \mathrm{ml}$ eluates were collected, counted for radioactivity, and their immunoreactive gastrin determined by RIA. Fractionation on starch gel electrophoresis was performed according to methods previously described (Berson and Yalow, 1971). Recovery of immuno- reactive gastrin from Sephadex columns and starch gel was generally greater than $80 \%$.

\section{Results}

The mean concentrations of plasma gastrin before and after secretin injection in 22 control subjects are shown in Fig. 1. The mean basal gastrin concentration in this group was $50 \pm 4(\mathrm{SEM}) \mathrm{pg} / \mathrm{ml}$. After injection of 1 unit Boots secretin/kg body weight a maximal decrease in gastrin concentration averaging $7, \mathrm{pg} / \mathrm{ml}$ was achieved at 10 minutes (Fig. 1; Table).

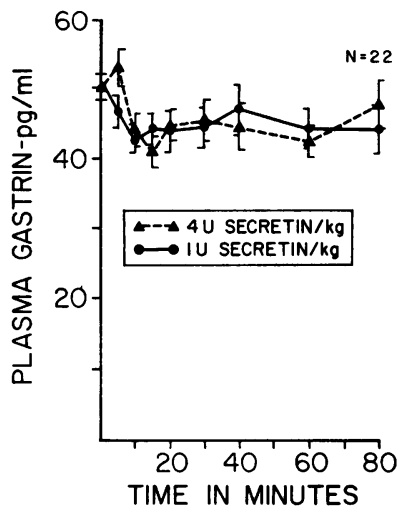

Fig. 1 Mean plasma gastrin concentrations in the fasting state and in response to intravenous injection of 1 and 4 units of secretin/ $\mathrm{kg}$ body weight in 22 control subjects. Secretin/kg: $\triangle----\Delta 4 U ; \bigcirc-1 U$.

\begin{tabular}{|c|c|c|c|c|c|c|c|c|c|c|}
\hline \multirow[t]{2}{*}{ Subject } & \multirow[t]{2}{*}{ Fasting } & \multicolumn{8}{|c|}{$\begin{array}{l}\text { Plasmas gastrin }(\mathrm{pg} / \mathrm{ml}) \\
\text { Minutes after secretin injection }\end{array}$} & \multirow[t]{2}{*}{$\begin{array}{l}\% B B G \text { in } \\
\text { fasting plasma }\end{array}$} \\
\hline & & 5 & 10 & 15 & 20 & 30 & 40 & 60 & 80 & \\
\hline $\begin{array}{l}\text { 1. } \mathrm{Ma} \\
\text { 2. } \mathrm{Cu} \\
\text { 3. } \mathrm{Vo} \\
\text { 4. } \mathrm{La} \\
\text { 5. } \mathrm{Fi} \\
\text { 6. } \mathrm{Ur} \\
\text { 7. } \mathrm{Si} \\
\text { 8. Os } \\
\text { 9. } \mathrm{Go} \\
\text { 10. } \mathrm{Sn} \\
\text { 11. } \mathrm{Wa} \\
\text { 12. } \mathrm{Ba} \\
\text { 13. } \mathrm{Mr} \\
\text { 14. Od } \\
\text { 15. } \mathrm{Co} \\
\text { 16. } \mathrm{No} \\
\text { 17. } \mathrm{Mo} \\
\text { 18. } \mathrm{Be} \\
\text { 19. } \mathrm{Ro} \\
\text { 20. } \mathrm{Pe} \\
\text { 21. } \mathrm{Pr} \\
\text { 22. } \mathrm{Se} \\
\mathrm{Mean} \pm \mathrm{SE}\end{array}$ & $\begin{array}{l}50 \\
19 \\
67 \\
28 \\
35 \\
28 \\
41 \\
71 \\
94 \\
41 \\
23 \\
57 \\
58 \\
64 \\
62 \\
90 \\
54 \\
44 \\
23 \\
50 \\
37 \\
73 \\
50 \pm 4\end{array}$ & $\begin{array}{l}50 \\
14 \\
40 \\
17 \\
30 \\
16 \\
40 \\
35 \\
85 \\
45 \\
22 \\
48 \\
69 \\
61 \\
84 \\
95 \\
69 \\
41 \\
30 \\
45 \\
38 \\
66 \\
47\end{array} 4$ & $\begin{array}{l}40 \\
12 \\
35 \\
16 \\
26 \\
14 \\
33 \\
34 \\
74 \\
24 \\
18 \\
49 \\
46 \\
43 \\
72 \\
93 \\
60 \\
49 \\
33 \\
47 \\
46 \\
82 \\
43+4\end{array}$ & $\begin{array}{r}-21 \\
35 \\
24 \\
21 \\
15 \\
25 \\
26 \\
59 \\
25 \\
23 \\
66 \\
53 \\
31 \\
71 \\
97 \\
61 \\
53 \\
33 \\
52 \\
36 \\
113 \\
45 \pm 5\end{array}$ & $\begin{array}{r}11 \\
8 \\
27 \\
26 \\
47 \\
25 \\
35 \\
-74 \\
22 \\
12 \\
- \\
50 \\
67 \\
78 \\
93 \\
47 \\
42 \\
28 \\
50 \\
34 \\
131 \\
45 \pm 6\end{array}$ & $\begin{array}{c}34 \\
27 \\
29 \\
14 \\
35 \\
36 \\
32 \\
- \\
113 \\
37 \\
12 \\
-74 \\
47 \\
65 \\
88 \\
46 \\
40 \\
21 \\
50 \\
22 \\
105 \\
45\end{array} 6$ & $\begin{array}{r}22 \\
20 \\
38 \\
24 \\
17 \\
22 \\
38 \\
29 \\
122 \\
37 \\
16 \\
53 \\
49 \\
49 \\
72 \\
90 \\
56 \\
46 \\
41 \\
52 \\
35 \\
110 \\
48 \pm 6\end{array}$ & $\begin{array}{r}37 \\
9 \\
34 \\
22 \\
28 \\
27 \\
24 \\
20 \\
88 \\
21 \\
21 \\
50 \\
44 \\
79 \\
67 \\
94 \\
55 \\
48 \\
36 \\
54 \\
36 \\
97 \\
45 \pm 6\end{array}$ & $\begin{array}{l}49 \\
13 \\
45 \\
22 \\
29 \\
29 \\
24 \\
37 \\
92 \\
33 \\
22 \\
45 \\
51 \\
67 \\
68 \\
90 \\
56 \\
45 \\
22 \\
51 \\
35 \\
67 \\
45 \pm 5\end{array}$ & $\begin{array}{r}63 \\
72 \\
58 \\
95 \\
100 \\
92\end{array}$ \\
\hline
\end{tabular}

Table Effect of injection of 1 unit Boots secretin/kg on plasma gastrin in control subjects 
One hour after completion of the first test the mean gastrin concentration had returned to $50 \mathrm{pg} / \mathrm{ml}$. Subsequent to the second dose, of 4 units secretin $/ \mathrm{kg}$, a mean maximum fall of $9 \mathrm{pg} / \mathrm{ml}$ was achieved in 15 minutes (Fig. 1). Eight of the 22 subjects showed no significant change in gastrin concentration after secretin injection. Each patient who responded to the $1 \mathrm{unit} / \mathrm{kg}$ dose also responded to the $4 \mathrm{unit} / \mathrm{kg}$ dose.

The eight patients whose gastrin levels were unchanged after secretin injection had significant pancreatic responses as measured by duodenal fluid volume and bicarbonate increases, thus ruling out the possibility of improper injection of the secretin in these subjects. In fact, these eight subjects were not distinguishable from the 14 others in terms of mean duodenal fluid volume and bicarbonate or basal gastrin levels.

In Fig. 2 are shown basal and post-secretin plasma gastrin concentrations in the PA patients. In each case, secretin injection was followed by a fall in gastrin levels, the minimum being reached in less than an hour. Patient $\mathrm{Ba}$ had the greatest and the most rapid reduction in plasma gastrin, falling from $1450 \mathrm{pg} / \mathrm{ml}$ to $700 \mathrm{pg} / \mathrm{ml}$ in 10 minutes after the 4 unit/kg dose.

The mean basal and post-prandial gastrin concentrations in seven subjects given test meals both with and without prior injection of 4 units Boots secretin/kg weight are shown in Fig. 3. The test meal alone provoked a mean maximal increase from a basal level of $60 \mathrm{pg} / \mathrm{ml}$ to $120 \mathrm{pg} / \mathrm{ml}$ in 20 minutes. The higher gastrin levels seen at the start of the second test meal (meal + secretin) are due to residual gastrin stimulated by the first test meal which was

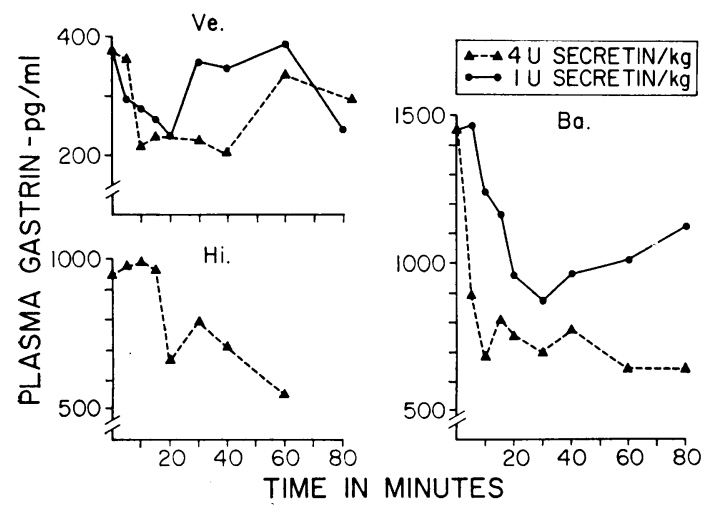

Fig. 2 Plasma gastrin concentrations in the fasting state and in response to intravenous injection of 1 (O-O) or 4 units $(\Delta---\Delta)$ of secretin/ $k g$ body weight in three patients with pernicious anaemia.

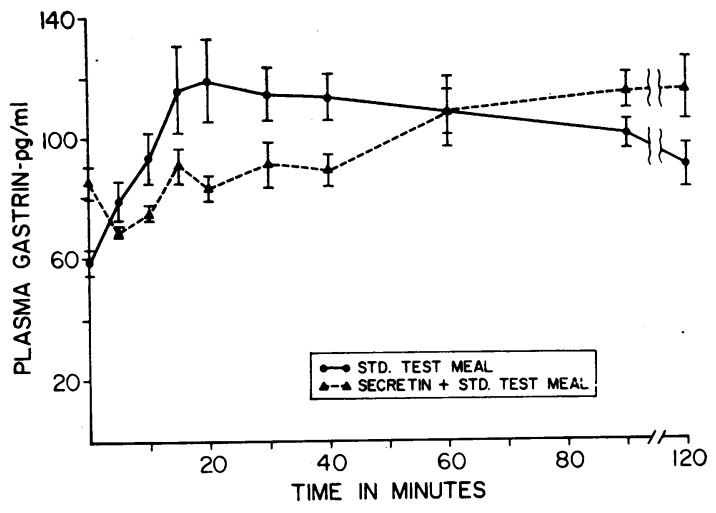

Fig. 3 Mean basal and post-prandial gastrin concentrations in seven subjects given test meals both with and without prior injection of 4 units secretin/ $/ \mathrm{kg}$ body weight.

given 130 minutes earlier. The initial specimen before the second test meal generally contained a greater proportion of big gastrin (BG) and heptadecapeptide gastrin (HG) than the basal specimen from the same subject. After secretin injection, the test meal provoked a mean maximal increase of only $30 \mathrm{pg} / \mathrm{ml}$ over the initial value. Furthermore, there was an initial significant fall in plasma gastrin and the peak was not reached before 120 minutes. In contrast, after the first test meal, plasma gastrin rose immediately, peaked by 20 minutes, and was returning towards fasting levels by 120 minutes.

Sephadex G-50 fractionation of fasting plasma samples from 12 control subjects demonstrated that the predominant component was generally big big gastrin (BBG). BBG was more than $90 \%$ of the total plasma immunoreactive gastrin in four of the 12 subjects. Patient No. shown in Fig. 4 (left top) was typical of this group. It was 50 to $90 \%$ in six subjects (Fig. 4, left middle) and less than $50 \%$ in only two subjects (Fig. 4, left bottom).

The four patients in whom BBG represented more than $90 \%$ of the total immunoreactive gastrin in fasting plasma had no significant lowering of basal gastrin by secretin injection. In two of these patients given feeding tests secretin did inhibit food-stimulated gastrin release. Significant depression of the gastrin level after secretin injection was observed only in patients in whom BG and HG were prominent components of the fasting gastrin. By comparing Sephadex gel fractionation patterns of basal (Fig. 5, left) and post-secretin (Fig. 5, right) plasma samples, it can be seen that the depression is due to diminished concentrations of these smaller hormonal forms. Thus, secretin suppression of gastrin in the fasting state of normal subjects is manifest only when 


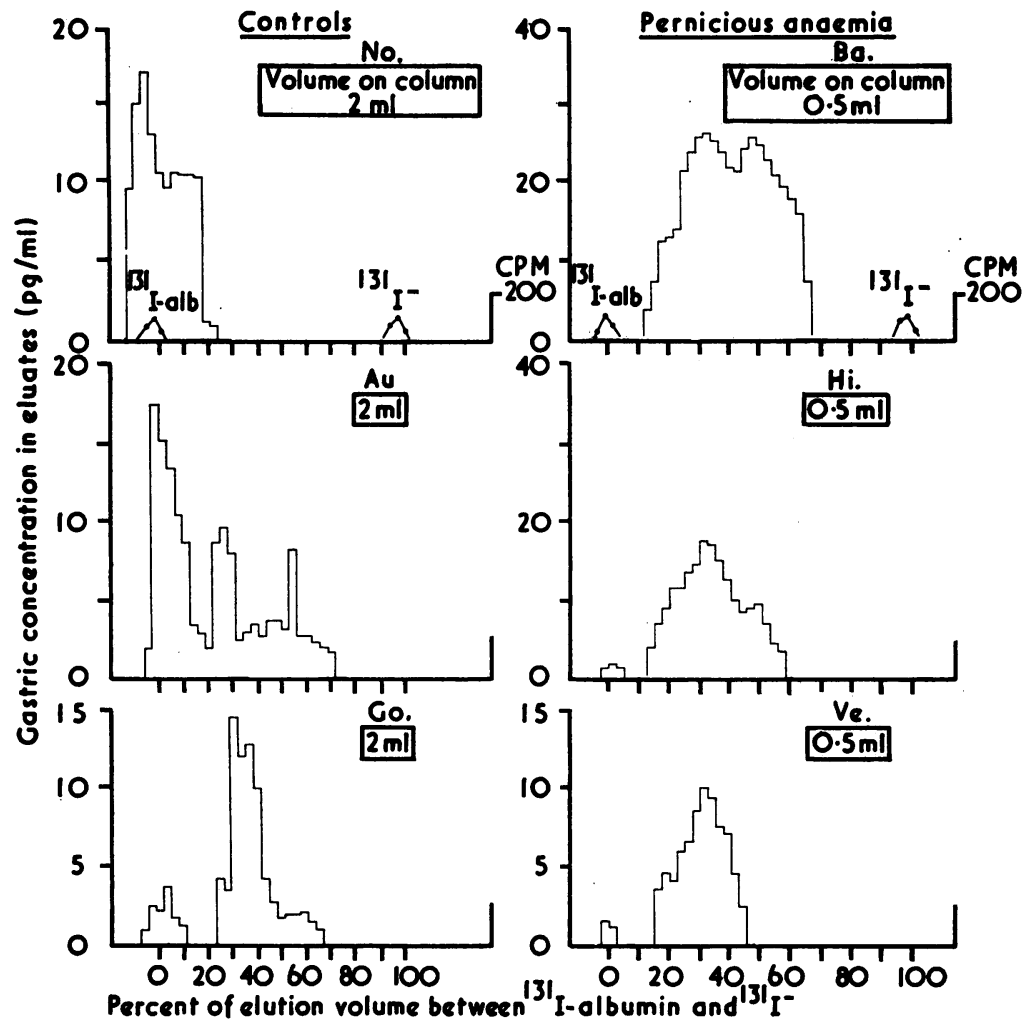

Fig. 4 Sephadex G-50 gel filtration of immunoreactive gastrin in fasting plasma specimens from three control subjects and three patients with pernicious anaemia. On Sephadex G-50 columns 'big big' gastrin $(B B G)$ elutes with ${ }^{131}$ I-albumin in the void volume, while the smaller gastrin forms elute from $20-70 \%$ of the way between ${ }^{131}$ I-albumin and ${ }^{131-}$.

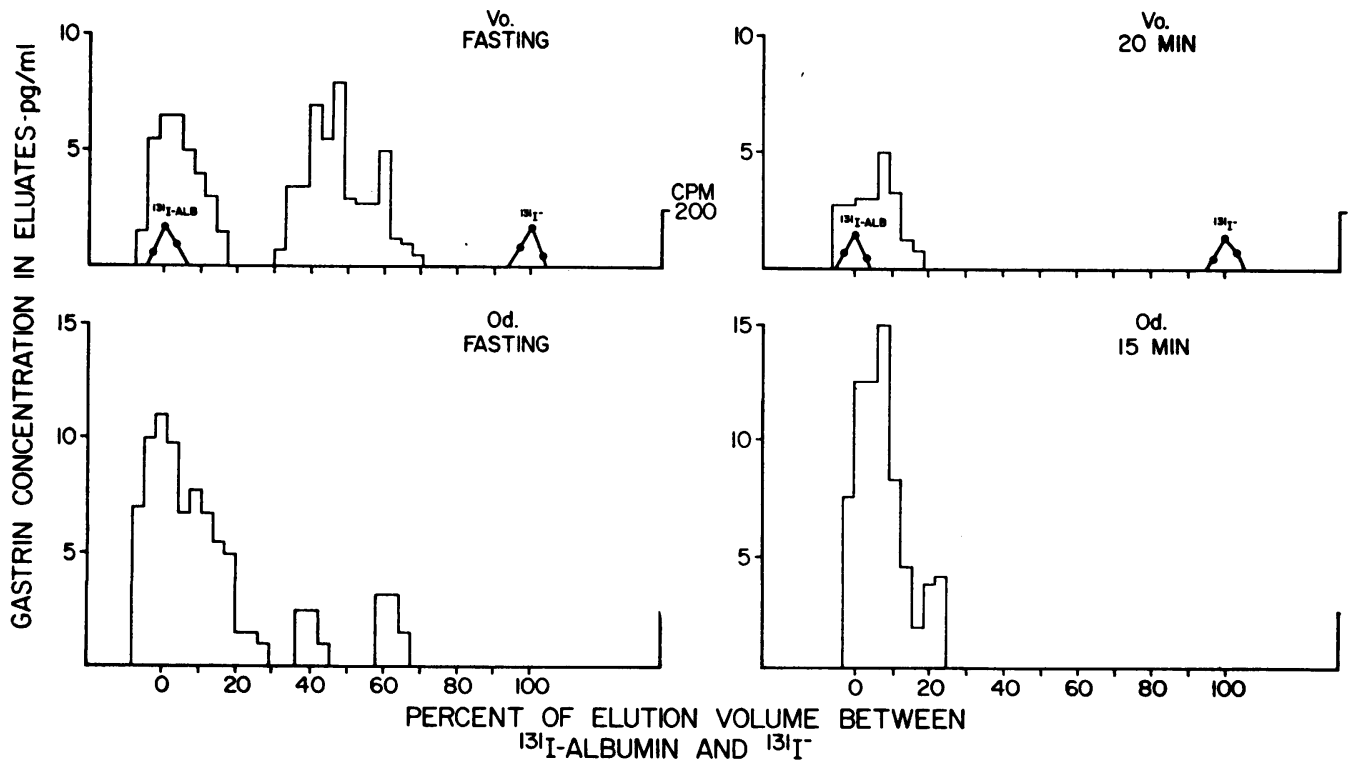

Fig. 5 Sephadex G-50 gel filtration of fasting (left) and post-secretin (right) plasma specimens in normal subjects showing post-secretin suppression of the smaller forms of immunoreactive gastrin. 
hormonal forms smaller than big big gastrin predominate.

In contrast with the results in control subjects, in PA patients BBG represented less than $5 \%$ of the total immunoreactive gastrin in the fasting specimen (Fig. 4, right). The resolution of BG and HG may be poor on Sephadex G-50gel fractionation without the use of superfine gel or longer columns than those we commonly employ. However, starch gel effects excellent resolution of BG and HG since HG migrates with approximately twice the electrophoretic mobility of BG (Yalow and Berson, 1970a). Earlier studies had demonstrated that BG is generally the principal immunoreactive gastrin component in the plasma of PA patients in the non-stimulated state (Yalow and Berson, 1970a; Yalow and Wu, 1973). Patient Hi (Fig. 6, bottom left) is typical of that group. However in the fasting plasma of patient $\mathrm{Ba}$ there were approximately equal amounts of BG and HG (Fig. 6, top left). The gastrin levels of both patients decreased after secretin injection but $\mathrm{Ba}$ responded with the greatest and most rapid fall, due primarily to the more rapid disappearance of HG (Fig. 6, right).

\section{Discussion}

The finding of heterogeneous forms of a peptide hormone in tissues and plasma inevitably necessitates consideration of the behaviour of these different forms in studies of hormonal physiology. The various forms of gastrin found in plasma have been shown to have relative concentrations which vary considerably, especially in different clinical conditions and in the basal, suppressed, and stimulated states (Yalow and Berson, 1970a; Yalow and Berson, 1971; Yalow and $\mathrm{Wu}, 1973)$, and to have very different turnover times (Straus and Yalow, 1974; Walsh et al., 1974). Thus, in analysing the effects of a potential inhibitor of gastrin secretion on plasma gastrin levels, it is necessary to bear in mind that the total immunoreactivity observed may represent the
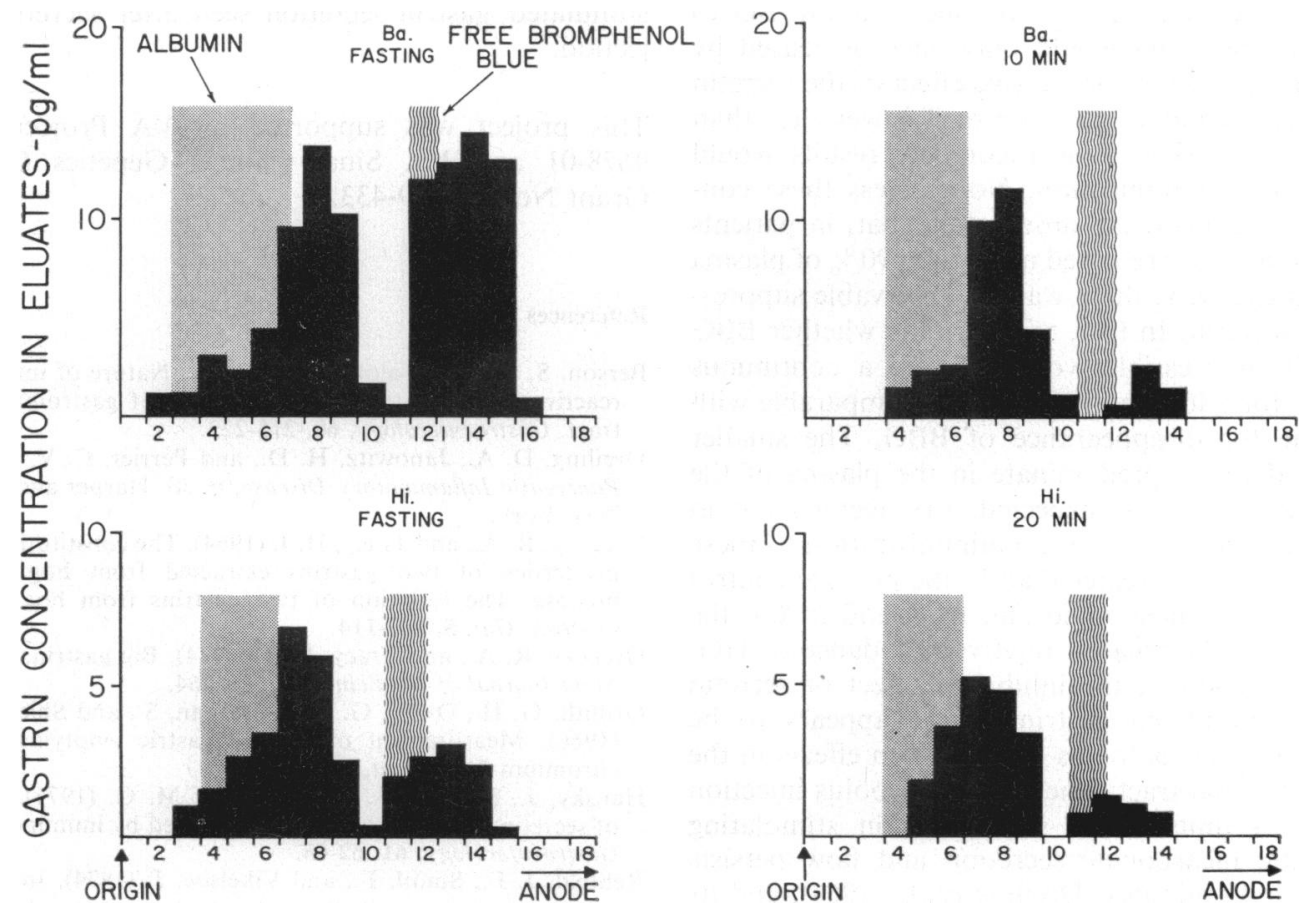

Fig. 6 Starch gel electrophoretic patterns of immunoreactive gastrin in fasting (left) and post-secretin (right) plasma specimens from two pernicious anaemia patients. In this system, heptadecapeptide gastrin (HG) migrates in advance of the bromphenol blue marker while big gastrin (BG) migrates just in advance of albumin. Patient Ba (top) has a greater proportion of HG in the fasting plasma. In both patients the post-secretin diminution in total plasma gastrin concentrations is seen to be caused by a more marked fall in HG levels with a lesser fall in BG levels. 
sum of several distinct hormonal forms whose relative concentrations may vary during the period of observation.

The studies presented here demonstrate that a bolus injection of secretin is capable of inhibiting gastrin release but that its apparent effect depends upon the distribution of the forms of gastrin in the plasma. The overall rate of disappearance of gastrin after total suppression of gastrin release would depend on the turnover time of each of the hormonal forms and its relative contribution to the total plasma immunoreactivity. We have previously shown that, after a bolus injection of gastrin to dogs, the half-times for disappearance of $\mathrm{HG}, \mathrm{BG}$ and BBG were three, nine, and 90 minutes respectively (Straus and Yalow, 1974). Walsh et al. (1974) have found similar rates for disappearance of $\mathbf{H G}$ and BG in dogs after discontinuation of a prolonged infusion of these peptides. It is not unreasonable to expect that the relative disappearance rates for the various hormonal forms in man are similar to those found in the dog. Thus, if a bolus injection of secretin were to suppress all forms of gastrin release for nine minutes, at the end of that time HG would have fallen to one-eighth its initial concentration, BG to one half, and BBG would only have decreased by less than $7 \%$. If the suppressive effect of the secretin bolus were of longer duration or if it were less than totally suppressive, these theoretical results would require some modification. Nonetheless these considerations explain the observation that, in patients in whom BBG represented more than $90 \%$ of plasma immunoreactivity, there was no observable suppression by secretin. In fact, to determine whether BBG is at all suppressible would require a continuous infusion for a long period, perhaps comparable with half-time for disappearance of BBG. The smaller hormonal forms predominate in the plasma of the PA patients and, as expected, the average fall in plasma gastrin after secretin administration to these patients is much greater than in the average control subject, being most rapid and profound in $\mathrm{Ba}$, the patient with the greatest relative abundance of HG.

The duration of the inhibitory effect of secretin on food-stimulated gastrin release appears to be about the same as for its other known effects in the gastrointestinal tract. The effect of a bolus injection of 1 to 4 units Boots secretin $/ \mathrm{kg}$ in stimulating pancreatic bicarbonate secretion and flow persists for about 40 minutes (Dreiling et al., 1964), and its inhibitory effect on gastrin-stimulated gastric hydrochloric acid secretion is of approximately the same duration (Wormsley and Grossman, 1964). Our data clearly indicate that, similarly administered, secretin also inhibits the food-stimulated major release of gastrin for about $\mathbf{4 0}$ minutes. These observations are in agreement with the earlier studies of Thompson et al. (1972). The inhibition of foodstimulated gastrin release represents the suppression of the smaller, more rapidly turned-over forms, since HG and BG have been shown to be released by feeding, while BBG is not (Yalow and Berson, 1971; Yalow and $\mathrm{Wu}, 1973)$. However, as a consequence of the late and prolonged rise in gastrin levels commencing at about 30 minutes, the integrated food-stimulated gastrin response after the test meal and secretin is approximately equal to that without secretin. The rise in plasma gastrin concentrations beginning at about 40 minutes is probably due to the decrease in the inhibitory effect of secretin at a time when approximately $50 \%$ of the meal is still in the stomach (Griffith et al., 1966). Because secretin suppressed gastrin release and probably inhibited gastrin-stimulated hydrochloric acid secretion, the gastric contents at $\mathbf{4 0}$ minutes after the second test meal were probably more alkaline than they were in the absence of secretin. The probable decrease in the acidity of the gastric contents coupled with the effect of secretin in delaying gastric emptying (Vagne and Andre, 1971) could explain the delayed rise in foodstimulated gastrin secretion seen after secretin injection.

This project was supported by VA Project No. 9678-01 and Mt. Sinai Clinical Genetics Center Grant No. GM 19-433.

\section{References}

Berson, S. A., and Yalow, R. S. (1971). Nature of immunoreactive gastrin extracted from tissues of gastrointestinal tract. Gastroenterology, 60, 215-222.

Dreiling, D. A., Janowitz, H. D., and Perrier, C. V. (1964). Pancreatic Inflammatory Disease, p. 30. Harper and Row: New York.

Gregory, R. A., and Tracy, H. J. (1964). The constitution and properties of two gastrins extracted from hog antral mucosa. The isolation of two gastrins from hog antral mucosa. Gut, 5, 103-114.

Gregory, R. A., and Tracy, H. J. (1974). Big gastrin. Mount Sinia Journal of Medicine, 40, 359-364.

Griffith, G. H., Owen, G. M., Kirkman, S., and Shields, R. (1966). Measurement of rate of gastric emptying using chromium-51. Lancet, 1, 1244-1245.

Hansky, J., Soveny, C., and Korman, M. G. (1971). Effect of secretin on serum gastrin as measured by immunoassay. Gastroenterology, 61, 62-68.

Rehfeld, J. F., Stadil, F., and Vikelsoe, J. (1974). Immunoreactive gastrin components in human serum. Gut, 15, 102-111.

Straus, E., Gerson, C. D., and Yalow, R. S. (1974). Hypersecretion of gastrin associated with the short bowel syndrome. Gastroenterology, 66, 175-180.

Straus, E., and Yalow, R. S. (1974). Studies on the distribution and degradation of heptadecapeptide, big, and big big gastrins. Gastroenterology, 66, 936-943. 
Thompson, J. C., Reeder, D. D., Bunchman, H. H., Becker, H. D., and Brandt, E. N. (1972). Effect of secretin on circulating gastrin. Annals of Surgery, 176, 384-392.

Vagne, M., and Andre, C. (1971). The effect of secretin on gastric emptying in man. Gastroenterology, 60, 421-424.

Walsh, J. H., Debas, H. T., and Grossman, M. I. (1974). Pure human big gastrin. Immunochemical properties, disappearance half-time, and acid-stimulating action in dogs. Journal of Clinical Investigation, 54, 477-485.

Walsh, J. H., Yalow, R. S., and Berson, S. A. (1971). The effect of atropine on plasma gastrin response to feeding. Gastroenterology, 60, 16-21.

Wormsley, K. G., and Grossman, M. I. (1964). Inhibition of gastric acid secretion by secretin and by endogenous acid in the duodenum. Gastroenterology, 47, 72-81.

Yalow, R. S., and Berson, S. A. (1970a). Size and charge distinctions between endogenous human plasma gastrin in peripheral blood and heptadecapeptide gastrins. Gastroenterology, 58, 609-615.

Yalow, R. S., and Berson, S. A. (1970b). Radioimmunoassay of gastrin. Gastroenterology, 58, 1-14.

Yalow, R. S., and Berson, S. A. (1971). Further studies on the nature of immunoreactive gastrin in human plasma. Gastroenterology, 60, 203-214.

Yalow, R. S., and Wu, N. (1973). Additional studies on the nature of big big gastrin. Gastroenterology, 65, 19-27.

\section{The November 1975 Issue}

\section{THE NOVEMBER 1975 ISSUE CONTAINS THE FOLLOWING PAPERS}

Peripheral blood and intestinal lymphocyte subpopulations in Crohn's disease R. G. STRICKLAND, GUNNAR HUSBY, W. C. BLACK, AND RALPH C. WILLIAMS, JR

Impaired anamnestic cellular immune response in patients with Crohn's disease S. G. M. MEUWISSEN, P. Th. A. SCHELleKENS, L. HUISMANS, AND G. N. TYTGAT

Mast cells and immunoglobulin $\mathrm{E}$ in inflammatory bowel disease G. LLOYD, F. H. Y. GREEN, H. FOX, V. MANI, AND L. A. TURNBERG

Viral antibody studies in pancreatic disease $P$. CAPNER, R. LENDRUM, D. J. JEFFRIES, AND GEOFFREY WALKER

Antibodies to Escherichia coli in chronic liver diseases A. E. SIMJEE, J. M. T. HAMILTON-MILLER, H. C. THOMAS, W. BRUMFITT, AND SHEILA SHERLOCK

Prednisone for chronic active liver disease: dose titration, standard dose, and combination with azathioprine compared w. H. J. SUMMERSKILL, MELVYN G. KORMAN, HELMUT V. AMMON, AND ARCHIE H. BAGGENSTOSS

Importance of the site of endoscopic gastric biopsy in ulcerating lesions of the stomach A. R. W. HATFIELD, G. SLAVIN, A. W. SEGAL, AND A. J. LEVI
Effect of urogastrone on gastric secretion and plasma gastrin levels in normal subjects J. B. ELDER, P. C. GANGULI, I. E. GILLESPIE, E. L. GERRING, AND H. GREGORY

Bile acids and colonic motility in the rabbit and the human. Part I The rabbit w. O. KIRWAN, A. N. SMITH, W. D. MITCHELL, J. DIANE FALCONER, AND M. A. EASTWOOD

Colonic pseudo-obstruction: a new complication of jejunoileal bypass R. E. BARRY, J. R. BENFIELD, P. NICELL, AND G. A. BRAY

Alterations in tissue ferritins in iron storage disorders LAWRIE W. POWELL, LEONARD V. MCKEERING, AND JUNE W. HALLIDAY

Jaundice due to carbimazole MICHAEL LUNZER, SHAO-NAN HUANG, JEAN GINSBURG, M. AHMED, AND SHEILA SHERLOCK

Involvement of the small intestine in systemic mast cell disease BRIAN B. SCOTT, G. J. HARDY, AND M. S. LOSOWSKY

Notes and activities

Notes on books

Copies are still available and may be obtained from the PUBLISHING MANAGER, BRITISH MEDICAL ASSOCIATION, TAVISTOCK SQUARE, LONDON WC1H 9JR, price $£ 2 \cdot 00$, including postage 